\title{
Nav $\beta 2$ knockdown improves cognition in APP/PS1 mice by partially inhibiting seizures and APP amyloid processing
}

\author{
Tao Hu ${ }^{1,2, *}$, Zhangang Xiao ${ }^{3,4, *}$, Rui Mao ${ }^{5, *}$, Bo Chen ${ }^{6, *}$, Min-Nan Lu, ${ }^{6, *}$, Jun Tong7,*, \\ Rong $\mathrm{Mei}^{8}$, Shan-Shan $\mathrm{Li}^{9}$, Zhi-Cheng Xiao ${ }^{10,11}$, Lian-Feng Zhang ${ }^{12}$ and Yan-Bin \\ Xiyang ${ }^{1}$ \\ ${ }^{1}$ Institute of Neuroscience, Basic Medical College, Kunming Medical University, Kunming, Yunnan, PR China \\ ${ }^{2}$ Department of Laboratory Medicine, The Third People's Hospital of Yunnan Province, Kunming, Yunnan, PR China \\ ${ }^{3}$ Laboratory of Molecular Pharmacology, Department of Pharmacology, School of Pharmacy, Southwest Medical University, \\ Luzhou, Sichuan, PR China \\ ${ }^{4}$ Key Laboratory of Medical Electrophysiology, Ministry of Education, School of Pharmacy, Southwest Medical University, \\ Luzhou, Sichuan, PR China \\ ${ }^{5}$ School of Stomatology, Kunming Medical University, Kunming, Yunnan, PR China \\ ${ }^{6}$ Experiment Center for Medical Science Research, Kunming Medical University, Kunming, Yunnan, PR China \\ 7 Physical Education Department, Kunming Medical University, Kunming, Yunnan, PR China \\ ${ }^{8}$ Department of Neurology, The First People's Hospital of Yunnan Province, Kunming, Yunnan, PR China \\ ${ }^{9}$ Basic Medical College, Kunming Medical University, Kunming, Yunnan, PR China \\ ${ }^{10}$ Institute of Molecular and Clinical Medicine, Kunming Medical University, Kunming, Yunnan, PR China \\ 11 Monash Immunology and Stem Cell Laboratories (MISCL), Monash University, Clayton, VIC, Australia \\ 12 Key Laboratory of Human Diseases Comparative Medicine, Ministry of Health, Institute of Laboratory Animal Science, \\ Chinese Academy of Medical Sciences(CAMS) \& Comparative Medicine Centre, Peking Union Medical College (PUMC), Beijing, \\ China \\ * These authors contributed equally to this work
}

Correspondence to: Yan-Bin Xiyang, email: xiyang_neuro@126.com

Keywords: voltage-gated sodium channels beta 2; Alzheimer's disease; APP/PS1 mouse; neuronal activity; cognition; Gerotarget Received: June 03, $2017 \quad$ Accepted: October 02, $2017 \quad$ Published: October 16, 2017

Copyright: Hu et al. This is an open-access article distributed under the terms of the Creative Commons Attribution License 3.0 (CC BY 3.0), which permits unrestricted use, distribution, and reproduction in any medium, provided the original author and source are credited.

\section{ABSTRACT}

Voltage-gated sodium channels beta 2 (Navß2, encoded by SCN2B) is a substrate of $\beta$-site amyloid precursor protein cleaving enzyme 1 (BACE1) and regulates cell surface expression of channels in neurons. Previous studies reported enhanced Nav $\beta 2$ processing by BACE1 in Alzheimer's disease (AD) model and patients. We investigated whether changes in Nav $\beta 2$ expression affect neuronal seizure and amyloid precursor protein (APP) processing in an AD mouse model. Our study used eight-month-old APP/presenilin 1 (PS1) mice and transgenic Nav $\beta 2$ knockdown [by $61 \%$ vs. wild type (WT)] APP/PS1 mice (APP/PS1/Nav $\beta 2-k d$ ), with age-matched WT and Nav $\beta 2$

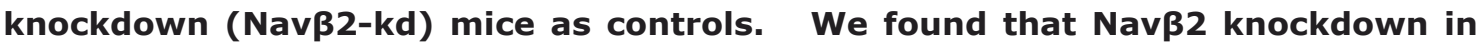
APP/PS1 mice partially reversed the abnormal Nav $\beta 2$ cleavage and the changes in intracellular and total Nav1.1a expression. It also restored sodium currents density in hippocampal neurons and neuronal activity, as indicated by EEG tracing; improved Morris water maze performance; and shifted APP amyloidogenic metabolism towards non-amyloidogenic processing. There were no differences in these indicators between WT and Nav $\beta 2-k d$ mice. These results suggest Nav $\beta 2$ knockdown may be a promising strategy for treating AD. 


\section{INTRODUCTION}

Alzheimer's disease (AD) is the most common form of dementia and affects as many as 35 million people worldwide [1]. AD incidence is expected to increase rapidly as the population ages. $\mathrm{AD}$ patient cognitive deficits and full-time care needs exact tremendous emotional and financial burden on family members and the health care system. Thus, developing viable anti$\mathrm{AD}$ therapies is an urgent necessity [2]. Although some approved treatments can alleviate $\mathrm{AD}$ symptoms, an improved understanding of $\mathrm{AD}$ pathogenesis is required to enable development of more effective, potentially curative treatments [3].

Epileptic activity can occur at early AD stages and might contribute to pathogenesis. Such seizures can hasten cognitive decline, highlighting the clinical necessity of early disease recognition and treatment [4]. In a familial AD mouse model, hypersynchronous network activity associated with seizure susceptibility precedes amyloid $\beta$ (A $\beta)$ plaque pathology and memory impairment [5]. Transgenic mouse models of AD exhibit brain-wide aberrant neuronal and epileptiform activity [6-10]. These aberrant neuronal activity and/or seizure modulate cognitive deficits in amyloid precursor protein (APP) transgenic mice and patients with amnestic mild cognitive impairment [6,9-12], and may directly contribute to cognitive deficits early in $\mathrm{AD}$ progression [13].

Voltage-gated sodium channels (VGSCs) are complex transmembrane glycoproteins responsible for action potentials in excitable cells. In addition to producing the large, transient current responsible for the action potential upstroke, action potential, sodium channels carry smaller currents at subthreshold voltages that contribute to spontaneous action potentials generation [14]. VGSCs consisted of a large $\alpha$ subunit, Nav1 (encoded by $S C N A$ gene), and associated auxiliary Nav2 subunits (Nav2.1-2.4, encoded by $S C N 1 B-S C N 4 B$ gene), which modulates channel activity. Voltage-gated sodium channels beta 2 ( $N a v \beta 2$, encoded by $S C N 2 B$ gene), an associated auxiliary subunits, is expressed in the central nervous system and in cardiac tissue [15]. Nav $\beta 2$ causes a depolarizing shift in Nav1.1 and Nav1.6 (encoded by $S C N 8 A$ ) voltage dependent activation and inactivation $[15,16]$. Nav2 upregulation and diffuse distribution along demyelinated axons may result in recovery from conduction block and clinical remission $[17,18]$. Nav $\beta 2$ has also been implicated in the pathogenesis of multiple sclerosis and experimental acute encephalitis (EAE), because it regulates channel cell surface expression in neurons [19], including that of Nav1, which modulates action potential propagation and neuronal activity [2022]. Our previous study associated increased hippocampal $S C N 2 B$ transcription in SAMP8 mice with learning and memory deficits, but the underlying mechanisms are still not understood [23]. $\beta$ secretase, also known as $\beta$-site amyloid precursor protein cleaving enzyme 1 (BACE1), initiates the production of the toxic $A \beta$ protein that plays a crucial role in early AD pathogenesis. Like APP, Nav 32 is a single transmembrane domain protein that is cleaved by BACE1 to produce a C-terminal fragment (CTF), which is subsequently cleaved by $\gamma$-secretase to release an intracellular domain (ICD) [22, 24]. Increased Navß32 processing and reduced Nav1.1 $\alpha$ surface expression in the transgenic APP mouse cortex suggests that both glutamatergic and GABAergic neurons are susceptible to enhanced Nav $\beta 2$ processing [13].

The link between Nav $\beta 2$, neuronal activity, and APP processing in $\mathrm{AD}$ has not yet been characterized. Given the roles of $\mathrm{Nav} \beta 2$ in $\mathrm{Na}+$ channel cell surface expression and cognitive (learning and memory) regulation, the present study investigated whether Nav $\beta 2$ expression changes affect neuronal activity, and/or seizure and spatial cognition via Nav1.1 $\alpha$ surface expression regulation and APP processing in an AD mice model.

\section{RESULTS}

\section{Transgenic mouse genotyping}

Potential transgenic $(\mathrm{Tg})$ founders were screened for the presence of transgene via PCR using mouse genomic DNA isolated from tail tissue. APP/presenilin 1 (APP/ PS1), Nav $\beta 2-k d, A P P / P S 1 / N a v \beta 2-k d$, and WT mice were screened by PCR (APP/PS1 Tg mice, 608bp; Nav $\beta 2-k d$ mice, 453bp; APP/PS1/Nav 32 mice, 608bp and 453bp; WT mice, 350bp, respectively) (Figure 1A). Nav $\beta 2$ levels in different transgenic mice were detected via qRT-PCR and western blotting. Nav $\beta 2$ knockdown reduced Nav $\beta 2$ protein (Figure 1B) and mRNA levels (Figure 1C-1D) by nearly $61 \%$ compared to WT mice (Supplementary Figures 1-2, Supplementary Tables 1-2).

\section{Navß2 cleavage and Nav1.1 $\alpha$ expression changes in APP/PS1 mice after Navß2 knockdown}

Western blot analysis showed Nav $\beta 2$ knockdown by $61 \%$ partially reversed the Nav $\beta 2$ cleavage and Nav1.1 $\alpha$ expression in APP/PS1/Nav $\beta 2-k d$ mice (vs. APP/PS1 mice). Nav 32 CTF (produced by BACE1 cleavage) and total Nav1.1 $\alpha$ increased in the hippocampal or cerebral cortex regions of APP/PS1 mice (vs. WT, $P<0.05$, Figure $2 \mathrm{~A}-2 \mathrm{C})$. Navß2 CTF levels in hippocampal/cortical lysates were lower in APP/PS1/Nav $\beta 2-k d$ mice than in APP/PS1 mice $(P<0.05)$. Surface biotinylation assays of hippocampus or cortex slices showed that Nav1.1 $\alpha$ was nearly absent on APP/PS1 mouse neuronal cell surface, but was restored in APP/PS1/Nav $\beta 2-k d$ mice (Figure 2D2F). Intracellular Nav1.1 $\alpha$ expression increased in APP/ 
$\mathbf{A}$

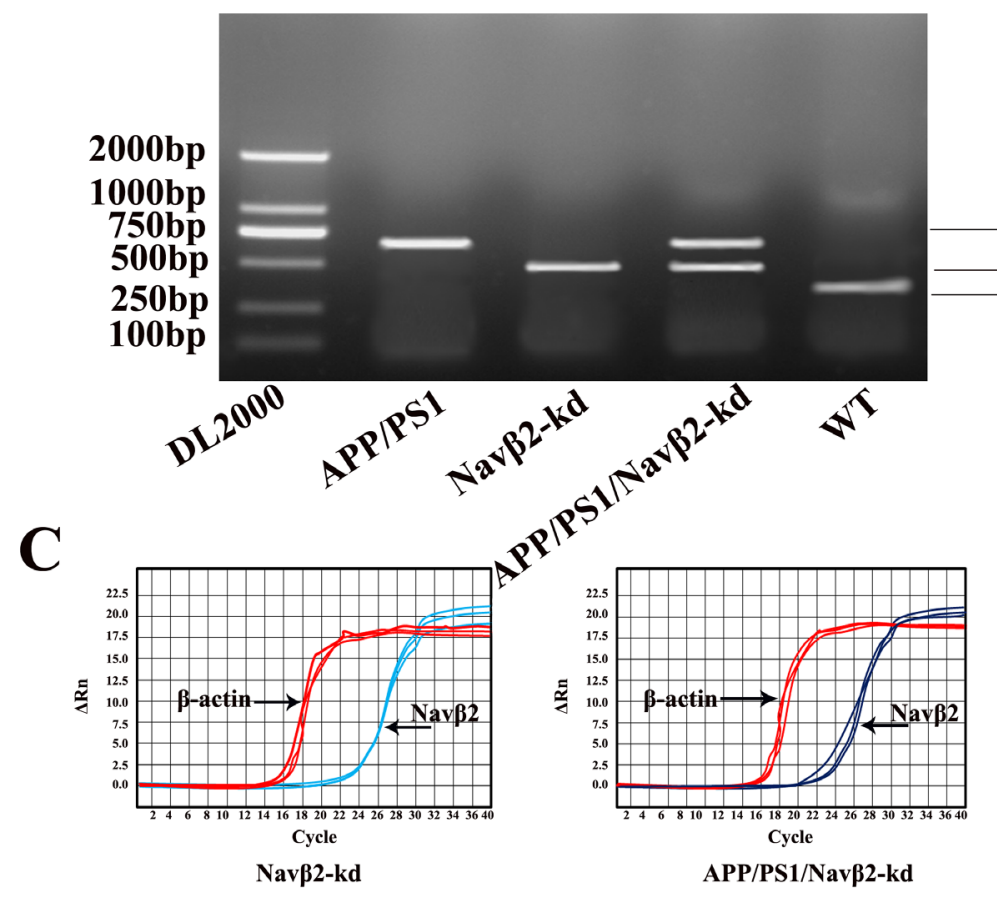

B Nav $\beta 2$

$608 \mathrm{bp}$ 453bp $350 \mathrm{bp}$

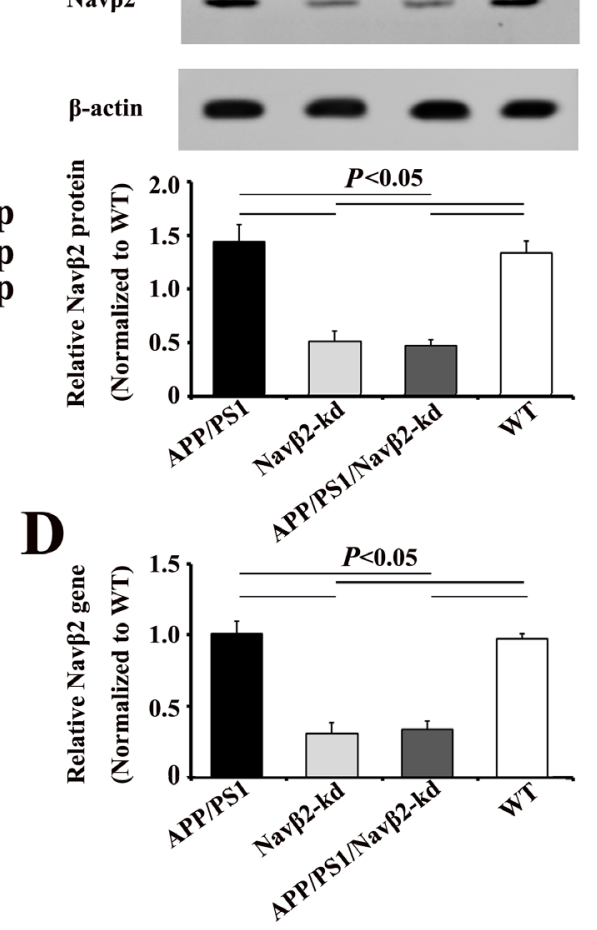

Figure 1: APP/PS1/Nav $\boldsymbol{\beta 2}$-kd transgenic mouse production. PCR products were separated by gel electrophoresis on a $1.5 \%$ agarose gel A. Nav $\beta 2$ protein in the Tg mouse hippocampus B. Navß2 expression in the Tg mouse hippocampus as detected by qRT-PCR. qRT-PCR amplification plots $\mathbf{C}$. and quantitative expression analysis D. Nav $\beta 2$ expression in Nav $\beta 2-k d$ and APP/PS1/Nav $\beta 2-k d$ mice was reduced by nearly $61 \%$, compared to WT mice. $(\mathrm{n}=9)$.
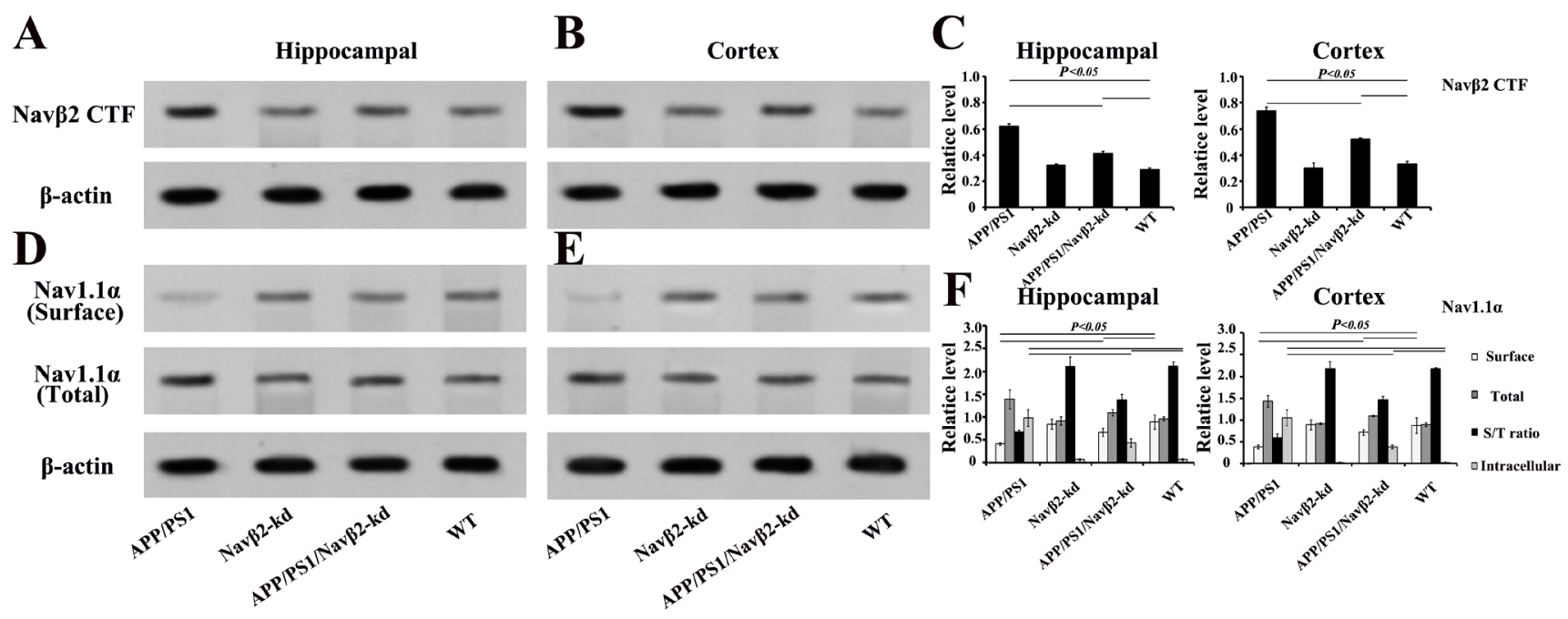

Figure 2: Nav alteration after Navß2 knockdown in Tg mice. Increased Nav $\beta 2$ CTF in hippocampal A. and cerebral cortex B.

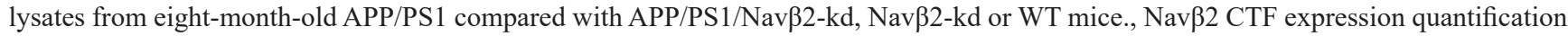
in different groups C. Decreased surface Nav1.1 $\alpha$ and increased total Nav1.1 $\alpha$ levels in hippocampal D. or cortical $\mathbf{E}$. tissues of eight-

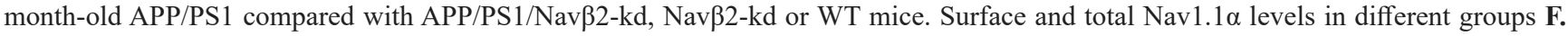
$(\mathrm{n}=15)$. 
PS1 mice (vs. WT, $P<0.05)$, and returned to lower levels following Nav $\beta 2$ knockdown $(P<0.05)$. Nav $\beta 2-\mathrm{kd}$ Tg mice without APP/PS1 mutation exhibited no changes in Nav $\beta 2$ cleavage and Nav1.1 $\alpha$ levels(vs. WT, $P>0.05$, Fig.2). These results suggest that Nav $\beta 2$ knockdown partially corrected the excessive Nav $\beta 2$ cleavage and aberrant Nav1.1 $\alpha$ transcellular trafficking observed in APP/PS1 mice.

\section{Navß2 knockdown recovered sodium currents in APP/PS1 mice}

The peak sodium current densities in hippocampal neurons decreased in APP/PS1 (vs. WT, $P<0.05$, Figure
$3 \mathrm{~A} \& 3 \mathrm{E})$ and partially recovered in APP/PS1/Nav $32-$ kd mice (vs. APP/PS1, $P<0.05$ ), as shown by sodium current I-V curves (Figure 3B) and peak currents densities (Figure 3E). The results suggest that Nav $\beta 2$ knockdown recovered sodium current densities in APP/PS1 mouse cells. However, Nav $\beta 2-k d$ mouse sodium current densities did not differ from those pf WT mice $(P>0.05$, Figure $3 \mathrm{C}$ $\& 3 \mathrm{E})$.

\section{Navß2 knockdown mitigated aberrant neuronal activity in APP/PS1 mice}

We performed video-EEG recordings and MWM test to determine whether $\operatorname{Nav} \beta 2$ knockdown affected
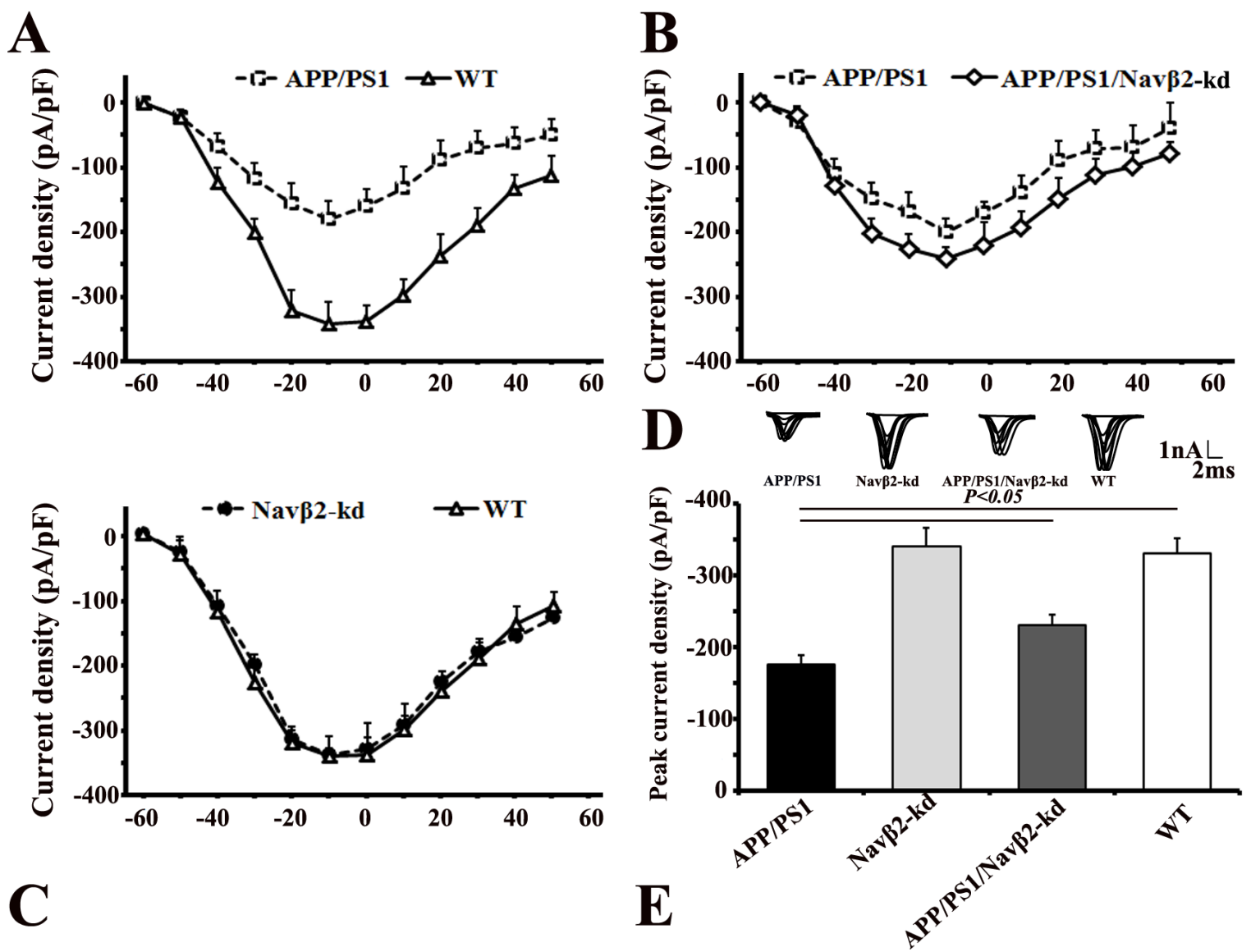

Figure 3: Navß2 knockdown recovered sodium currents in APP/PS1 Tg mice. Whole cell recordings were performed using hippocampal neurons from APP/PS1, Nav $\beta 2-k d$, APP/PS1/Nav $32-k d$, and WT mice. Fast sodium currents were activated by stepped depolarizations, following pharmacological suppression of voltage-dependent calcium and potassium currents with $\mathrm{Cd} 2+$ and $\mathrm{Cs}+$, respectively. Peak sodium current amplitude at each voltage step (I-V) was normalized to the neuron's capacitance and plotted as a function of the command potential (28). Hippocampal slices of APP/PS1, Nav $\beta 2-k d$, APP/PS1/Nav $\beta 2-k d$, and WT mice (6-8 weeks) were used for whole cell recordings of voltage-gated sodium currents. Depolarizing voltage steps, from $-60 \mathrm{mV}$ to $60 \mathrm{mV}$ (10 mV increments) in neurons from APP/PS1, Nav $\beta 2-k d$, APP/PS1/Nav $\beta 2-k d$, and WT mice, were performed to elicit the corresponding sodium current responses. Sodium currents were reduced in hippocampal neurons from APP/PS1 mice. Nav $\beta 2$ knockdown partially recovered sodium currents in APP/PS1/Nav $\beta 2-k d$ mice (vs. APP/PS1, $P<0.05$ ). There was no difference between Nav $\beta 2-k d$ and WT mice $(P>0.05)$. Current-voltage relationships for sodium current densities in APP/PS1 and WT mice A in APP/PS1, APP/PS1/Navß2-kd, and WT mice B., and in Nav $\beta 2-$ $\mathrm{kd}$ and WT mice $\mathbf{C}$. Representative sodium current responses elicited by depolarizing voltage steps $\mathbf{D}$. Peak current densities in mice with different genotypes $\mathbf{E}$. $(\mathrm{n}=15)$. pF, picofarads. 
neuronal activity. We found that eight-month-old APP/ PS1 mice exhibited spike-wave discharges (SWDs) and abnormal EEG patterns compared to WT mice (Figure 4A). These abnormal EEG patterns were at least partially mitigated in Nav $\beta 2$ knockdown APP/PS1 mice (Figure 4A). APP/PS1 mice exhibited longer durations of higher frequency brain activity with some obvious spikes. APP/ PS1/Nav $32-k d$ mice, with decreased Nav $\beta 2$ cleavage and total levels of Nav1.1 $\alpha$, exhibited more comparative normal neuronal activity without epileptiform discharges (vs. APP/PS1, $P<0.05$, Figure 4B). However, this recovery did not reach normal levels (APP/PS1/Nav $\beta 2-k d$ vs. WT, $P<0.05$, Figure 4B). There was no difference between Nav $\beta 2$-kd and WT mice $(P>0.05)$.

\section{Navß2 knockdown improved learning and memory of APP/PS1 mice}

Tow-way repeated-measures ANOVA (RM ANOVA) revealed that the average escape latency of the hidden platform progressively decreased over time in all groups. APP/PS1 Tg mice needed more time to find the hidden platform underwater than both WT $(\mathrm{F}=25.28, P<0.000)$ and APP/PS1/Navß2-kd mice $(\mathrm{F}=17.15, P<0.000)$ (Figure $5 \mathrm{~A})$. At the end of the hidden platform test, the platform was removed for the probe trial and all mice were allowed to swim for $60 \mathrm{~s}$ to assess their memory for the platform's location. APP/PS1 mice showed lower percentages of time in the target quadrant (tow-way ANOVA Tukey's Test, $P<0.05$, Figure 5B), percentages of path in the target quadrant (tow-way ANOVA Tukey's Test, $P<0.05$, Figure $5 \mathrm{C})$ and numbers of platform crossings than age-matched WT (tow-way ANOVA Tukey's Test, $P<0.05$, Figure 5D).

Nav $\beta 2$ knockdown in APP/PS1 mice partially improved MWM performance, although spatial memory didn't recover to WT levels. APP/PS1/Nav $\beta 2-k d$ mice took less time to find the hidden platform $(\mathrm{F}=9.41, P<0.05$, Figure 5A), showed a significant preference for the target quadrant $(P<0.05$, Figure $5 \mathrm{C})$, had lower percentages of path in the target quadrant $(P<0.05$, Figure 5D), and fewer platform crossings $(P<0.05$, Figure $5 \mathrm{E})$ than age matched

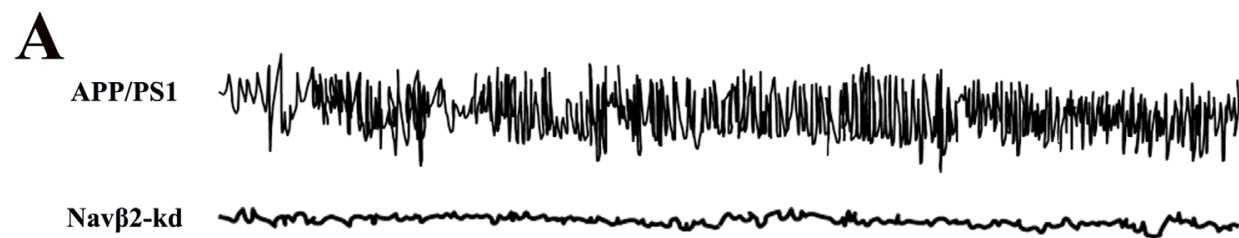

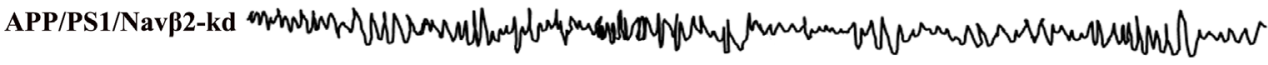

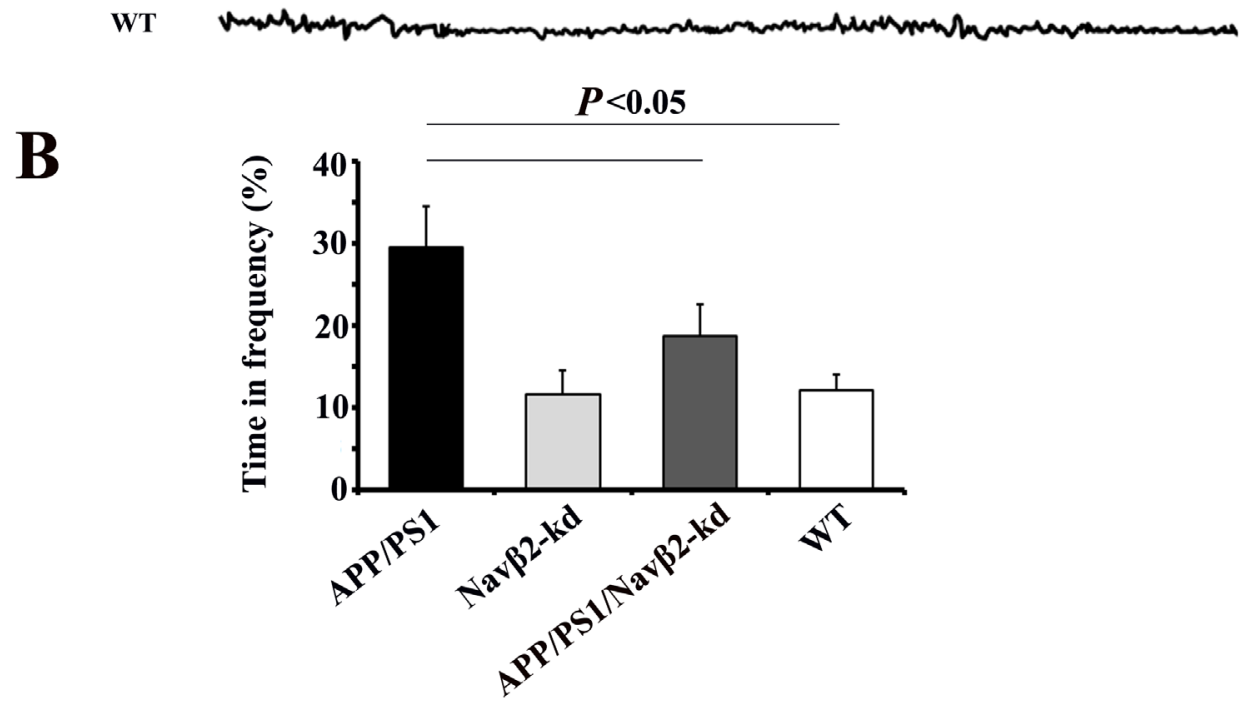

Figure 4: Navß2 knockdown reversed aberrant neuronal activity in APP/PS1 mice. EEG recordings showed increased brain activity amplitudes and frequencies in eight-month-old APP/PS1 mice, and this was partially reversed in APP/PS1/Nav $32-\mathrm{kd}$ mice A. Percentage of time at frequency $>6 \mathrm{~Hz} \mathbf{B}$. APP/PS1 mice exhibited longer durations of higher frequency activity than APP/PS1/Nav $\beta 2-k d$, Nav $\beta 2-k d$ and WT mice $(n=15)$. 
APP/PS1 mice. Additionally, we observed no spatial learning and memory performance difference in eightmonth-old Nav $\beta 2$-kd mice compared to age matched WT mice $(P>0.05)$.

\section{APP processing and A $\beta$ production changes in APP/PS1/Navß2-kd mice}

To determine whether Nav $\beta 2$ alteration is related to APP metabolism, we measured A $\beta 40, \mathrm{~A} \beta 42$, sAPP $\alpha$, and SAPP $\beta$ levels produced by primary cultured mouse neurons. We detected higher $\mathrm{A} \beta 40$ and $\mathrm{A} \beta 42$ levels, and an increased $A \beta 42 / A \beta 40$ ratio in APP/PS1 mouse-derived cells (vs. WT, $P<0.05$, Figure 6A-6C). Decreased A $\beta 40$ and $\mathrm{A} \beta 42$ deposition was observed in APP/PS1/Nav $\beta 2-\mathrm{kd}$ mice (vs. APP/PS1, $P<0.05$, Figure 6A-6B). There were no differences in $A \beta 40$ and $A \beta 42$ levels between WT and Nav $\beta 2$-kd mice $(P>0.05)$.

ECLIA results showed $\mathrm{SAPP} \alpha$ downregulation (vs. WT, $P<0.001$ ), sAPP $\beta$ upregulation (vs. WT,

B Hidden platform test
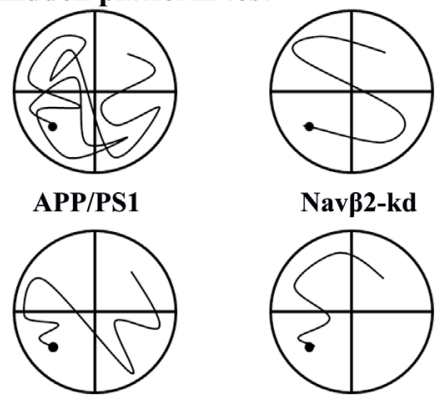

APP/PS1/Navß2-kd

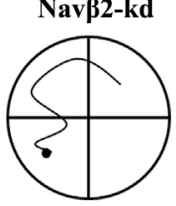

WT

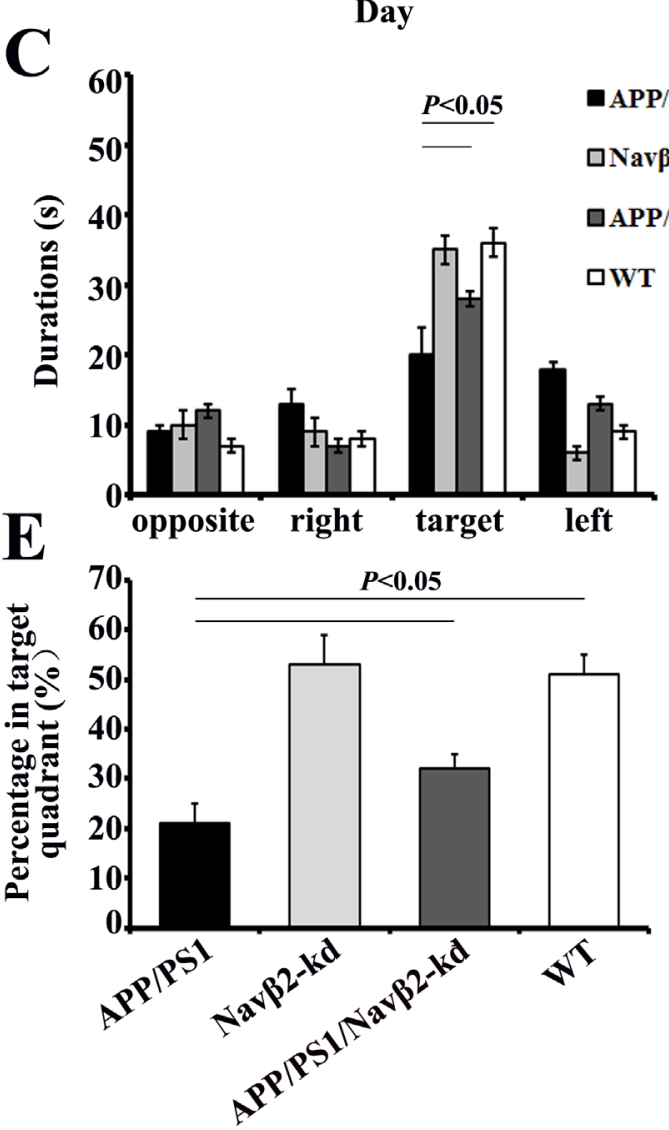

D

Probe test
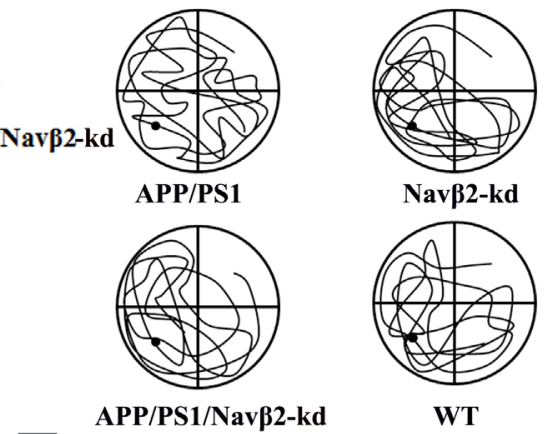

WT

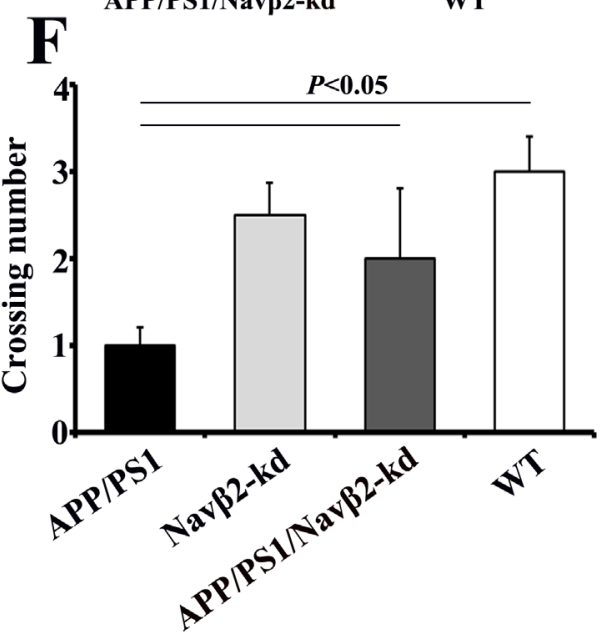

Figure 5: Spatial learning and memory were improved in APP/PS1/Navß2-kd Tg mice. Escape latencies over five days in the hidden platform test $\mathbf{A}$. and typical training traces (fifth day) B. Comparisons of the percentage of time spent in the target quadrant $\mathbf{C}$., percentage of path travelled in the target quadrant D., and number of target crossings in the probe test E. for APP/PS1, Nav $\beta 2-\mathrm{kd}$, APP/PS1/ Navß2-kd, and WT mice. Typical probe traces F. $(\mathrm{n}=15)$. 
$P<0.001$ ), and decreased sAPP $\alpha / \mathrm{sAPP} \beta$ ratios (vs. WT, $P<0.05$ ) in APP/PS1 mouse-derived cells (Figure 6D6F). APP/PS1/Nav $\beta 2-k d$ mouse-derived cells showed sAPP $\alpha$ upregulation (vs. APP/PS1, $P<0.05$ ), sAPP $\beta$ downregulation (vs. APP/PS1, $P<0.001$ ), and an increased $\mathrm{sAPP} \alpha / \mathrm{sAPP} \beta$ ratio (vs. APP/PS $1, P<0.001$ ). There was no difference between Nav $\beta 2-\mathrm{kd}$ and WT mice $(P>0.05)$.

\section{DISCUSSION}

Previous studies demonstrated that five- to sixmonth-old pre-plaque APP mice exhibited Nav1.1 $\alpha$ upregulation and increased Nav $\beta 2$ CTF levels [13]. We examined whether Nav $\beta 2$ knockdown regulates Nav $\beta 2$ cleavage and Nav1.1 $\alpha$ expression in an AD mouse model. Nav 32 knockdown in APP/PS1 mice reversed abnormal Nav $\beta 2$ cleavage and both intracellular and total Nav1.1 $\alpha$ expression, recovered sodium currents densities in hippocampal neurons, partially rectified abnormal EEG tracing, improved MWM performance, and shifted APP/ PS1 mutation-induced APP amyloidogenic metabolism toward non-amyloidogenic processing. Thus, aberrant neuronal network excitability attributed to cognitive deficits in APP/PS1 mice might be at least partially remedied by Nav $\beta 2$ knockdown. However, Nav $\beta 2$ cleavage, Nav1.1 $\alpha$ levels, sodium currents densities, and spatial learning and memory were unchanged in Nav $\beta 2$ $\mathrm{kd} \mathrm{Tg} \mathrm{mice} \mathrm{lacking} \mathrm{the} \mathrm{APP/PS1} \mathrm{genetic} \mathrm{background}$ compared to WT mice.

Normal Nav $\beta 2$ expression and function are necessary for Nav1.1 $\alpha$ transcellular trafficking and surface expression [30]. Nav $\beta 2$ CTF produced by BACE1 is subsequently cleaved by $\gamma$-secretase to produce Nav $\beta 2$ ICD, which translocates to the nucleus and triggers expression of the pore-forming Nav1.1 $\alpha$ subunit [22, 24]. Nav $\beta 2$ knockdown partially restored Nav $\beta 2$ processing and Nav1.1 $\alpha$ expression.

VGSCs are responsible for action potentials in excitable cells. In addition to producing the large, transient current responsible for the action potential upstroke, sodium channels carry smaller currents at subthreshold voltages that contribute to the generation of spontaneous action potentials [14]. Excessive Nav $\beta 2$ cleavage induced by BACE1 overexpression in a Tg mouse model retained intracellular levels and reduced surface levels of Nav1.1 $\alpha$, leading to decreased action potential propagation and neuronal activity $[21,22]$. In agreement with our findings, alterations in cortical Nav1.1 $\alpha$ levels were associated with aberrant EEG activity, and correlated inversely with water maze performance [13]. We proposed that Nav $\beta 2$ knockdown might partially recover sodium current densities and aberrant epileptic seizures incidences in AD model by altering Nav $\beta 2$ cleavage and retaining surface Nav1.1 $\alpha$ levels.

Epileptic seizures are common in AD patients, and hyper-excitability is detected in AD transgenic mouse
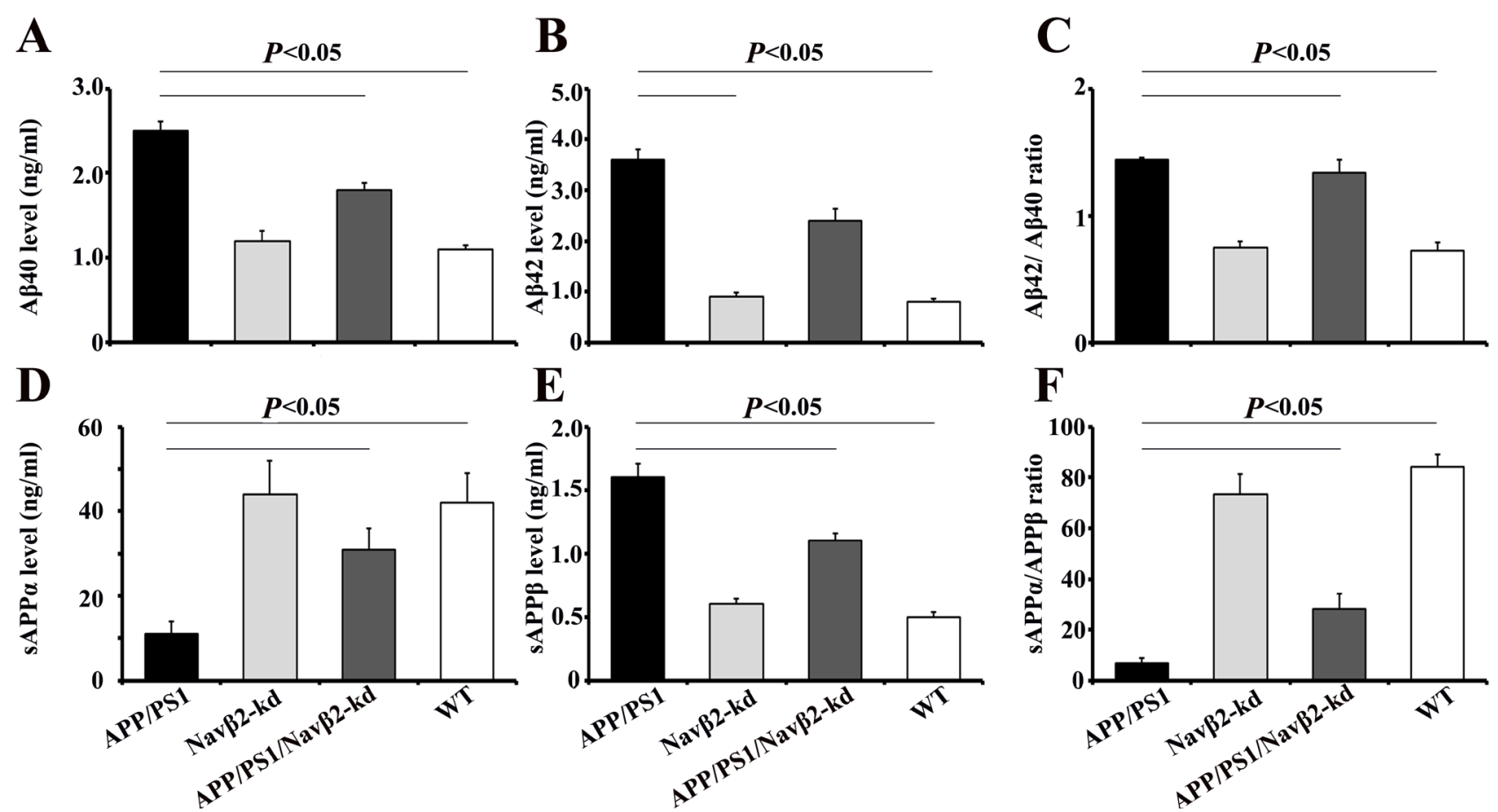

Figure 6: Navß2 knockdown altered APP processing in an APP/PS1 cell model. APP amyloidogenic processing inhibition was confirmed by ELISA measurements of A $\beta 40$ A. and A $\beta 42$ B. production in culture medium of hippocampus neurons from APP/PS1, Nav $\beta 2-k d$, APP/PS1/Nav $\beta 2-k d$, and WT mice. A $\beta 42 / A \beta 40$ ratio C. Results are shown as A $\beta$ levels in ng/ml. Soluble APP $\alpha$ D. and sAPP $\beta$ E. levels in culture medium of cells sourced from mice were monitored via ECLIA. sAPP $\alpha / A P P \beta$ ratio was calculated as shown in $\mathbf{F}$. Results are given as sAPP in $\mathrm{ng} / \mathrm{ml}(\mathrm{n}=15)$. 
brains [31]. Such aberrant increases in network excitability and compensatory inhibitory mechanisms in the hippocampus may contribute to $\mathrm{AD}$-associated cognitive deficits $[6,11,32]$. EEG indicates the average electrical activity of the neuronal populations on a large-scale level, and are widely utilized as a noninvasive brain monitoring tool in cognitive neuroscience and as a diagnostic tool for epilepsy and sleep disorders [29]. Coordinated cortical activity and oscillations strongly influence function of the hippocampus, which receives spatial information from different cortical areas [33, 34]. Spatial information encoding depends on integration of information from numerous dynamically interconnected regions $[35,36]$.

Deposition of $A \beta$, derived from APP by sequential proteolytic cleavage, forms the neuritic plaques that are the pathological hallmark of AD. APP cleavaged by $\alpha$-secretase precludes $A \beta$ generation as part of the nonamyloidogenic pathway. Conversely, APP processed via amyloidogenic pathway generates a membrane-anchored C-terminal fragment, which is further cleaved by the $\gamma$-secretase complex to generate the $\mathrm{A} \beta$ peptides. The $\mathrm{A} \beta$ isoforms, $A \beta 40$ and $A \beta 42$, are the major constituents of $\mathrm{AD}$-associated senile plaques [37]. Our data detected higher A $\beta 40, \mathrm{~A} \beta 42$, and sAPP $\beta$ levels, and lower sAPP $\alpha$ and $\mathrm{sAPP} \alpha / \mathrm{sAPP} \beta$ ratio in APP/PS1 mice. Nav $\beta 2$ knockdown in these mice decreased $A \beta 40$ and $A \beta 42$ deposition and sAPP $\beta$ production, as well as increased sAPP $\alpha$ levels and sAPP $\alpha /$ APP $\beta$ ratios. Ectodomain shedding indicated by soluble APP $\alpha(\operatorname{sAPP} \alpha)$ and $\operatorname{sAPP} \beta$ production is the first step in non-amyloidogenic and amyloidogenic processing, respectively [38]. Nav 32 knockdown shifted APP/PS1 mutation-induced APP amyloidogenic metabolism towards non-amyloidogenic processing.. Li, et al. reported that APP/AICD modulates Nav1.6 sodium channels through a Go-coupled JNK pathway, which is dependent on APP phosphorylation at Thr668 [28]. Others revealed that $S c n 2 b-/-$ mice are protected from axonal damage during EAE due Nav1.6 downregulation along demyelinated axons, thus reducing the harmful effects of the predicted persistent $\mathrm{Na}+$ current. The absence of $\beta 2$ may also attenuate the persistent $\mathrm{Na}+$ current mediated by $\mathrm{Na}+$ channels in demyelinated lesions [19]. Moreover, treatment with $\mathrm{A} \beta$ increased $\mathrm{Nav}$ and Nav1.6 expression in cultured neurons, indicating that A $\beta 1-42$ could alter the number of Nav channels [39]. Thus, our findings suggested that Nav $\beta 2$ expression might indirectly or directly modulate APP metabolism by interacting with Nav1.6, although further investigation was necessary.

Our previous study demonstrated that a downregulation of $S C N 2 B$ (by $60.68 \%$ ) improved learning and memory, and increased hippocampal synaptic excitability in aged (18-month-old) mice, and did not impact adult (eight-month-old) mice [21]. Our present work found no differences in Nav $\beta 2$ cleavage, surface Nav1.1 $\alpha$ levels, sodium currents densities, neuronal activity, or spatial learning and memory between eight-month-old Nav $\beta 2-k d$ and age-matched WT mice.. O'Malley, et al. demonstrated that the regulation of $\mathrm{Na}+$ channel cell surface expression and function within special microenvironments, such as neuronal injured or demyelination, is critical to neuronal survival and recovery [19]. Therefore, we assumed that Nav $\beta 2$ downregulation protected neurons by a cleavage condition-depended mechanism. Normally, Nav $\beta 2$, as an auxiliary subunit, assists Nav1 subunit in maintaining sodium gate function. Nav $\beta 2$ pathological cleavage triggered during early stage AD reduces surface Nav1.1 $\alpha$ levels, induces aberrant neuronal activity, amyloidogenic processing, and ultimately cognitive deficit.

In conclusion, we demonstrated that Nav $\beta 2$ knockdown protected neurons and improved spatial learning and memory by partially reversing the excessive Nav $\beta 2$ cleavage, aberrant Nav1.1 $\alpha$ transcellular trafficking, reduced sodium channel densities and neuronal activity, and APP amyloidogenic metabolism observed in aged APP/PS1 mice. Our findings suggest that Nav $\beta 2$ knockdown might be a promise anti-AD therapeutic strategy.

\section{MATERIALS AND METHODS}

\section{Ethics approval}

Animal use and care were in conducted in accordance with guidelines provided in the Guide for the Care and Use of Laboratory Animals published by the US National Institutes of Health (NIH Publication No. 8523, revised 1996) and in the Care and Use Guidelines of Experimental Animals established by the Research Ethics Committee of Kunming University of China (Permit Number: kmu-eac-2016019). All surgical procedures were performed under diethyl ether anaesthesia, and all efforts were made to minimize suffering.

\section{Animal model generation}

APPswe/PS1 1 E9 (APP/PS1, C57BL/6J) mice, in which APP overexpress with the Swedish mutation and PS1 is deleted in exon 9, rapidly accumulates A $\beta$ plaques at eight months of age. Nav $\beta 2$ knockdown (Nav $\beta 2-k d)$ transgenic (Tg) mice with $\mathrm{C} 57 \mathrm{BL} / 6 \mathrm{~J}$ genetic background were generated and bred in our lab as previously described [23]. Our previous study associated increased hippocampal Nav $\beta 2$ in aged SAMP8 mice with learning and memory deficits. A $60.68 \% S C N 2 B$ transcription reduction improved hippocampus-dependent spatial recognition memory and field excitatory postsynaptic potential (fEPSP) long-term potentiation (LTP) slope in aged mice [23]. The present study investigated the 
neuroprotective effects of Nav $\beta 2$ knockdown in APP/PS1 AD mouse model.

APP/PS1, APP/PS1/Nav $\beta 2-k d$ mice with C57BL/6J genetic background were generated and bred by our collaborators in the Institute of Laboratory Animal Science (Chinese Academy of Medical Sciences \& Comparative Medicine Centre, Peking Union Medical College, Beijing, China). The $S C N 2 B$ silencing vector and reconstruction plasmid were designed as previously described [23]. The transgene was then isolated from the cloning plasmid, purified using Avr II digestion, and microinjected into fertilized APP/PS1 mouse eggs.

Overexpression of human APP with the Swedish (K594M/N595L) mutation, deletion of PS1 in exon 9 driven by the mouse prion protein promoter, and Nav $\beta 2$ knockdown were confirmed by PCR genotyping of APP/ PS1/Navß2-kd Tg mouse tail tissue [23, 25] (APP/PS1 Tg mice, 608bp; Nav $\beta 2-k d$ mice, 453bp; APP/PS1/Nav 32 mice, 608bp and 453bp; WT mice, 350bp). Potential Tg founders were screened for the presence of the transgene via PCR using mouse genomic DNA isolated from tail biopsies. The following primers were used for Nav $\beta 2-\mathrm{kd}$ mice: sense, 5'GCTCGGTGTTGCTGTGAT 3'; antisense, 5'TGATGGGCTACGGCTTCT 3'. The following primers were used for APP/PS1 mice:: transgenic forward, 5'AAT AGA GAA CGG CAG GAG CA 3', transgenic reverse, 5'GCC ATG AGG GCA CTA ATC 3'; Internal control forward, 5'CTA GGC CAC AGA ATT GAA AGA TCT 3', Internal control reverse, 5' GTA GGT GGA AAT TCT AGC ATC ATC C 3'. RT-PCR products were electrophoresed in $1.2 \%$ agarose gel, stained with ethidium bromide (EB), and visualized using an ultra violet gel imager (BIO-GEL, BIO-RAD). Image analysis was performed by Imager J 6.0 (LIVE Science, USA).

Since the female APP/PS1 mice develop cognitive deficits faster than their male counterparts, only female mice were used in this study [26]. Because APP/PS1 induced greater cognitive impairment in aged mice, experiments were performed using APP/PS1/Nav $\beta 2-\mathrm{kd}$ triple Tg mice aged eight months. Age-matched APP/PS1, Nav $\beta 2-k d$ and wild type (WT) mice were used as controls.

\section{Western blot}

Hippocampus and cortex from the mice with different genotypes ( $\mathrm{n}=15$ per group) were harvested and separately homogenized on ice in $10 \mathrm{mM}$ Tris-HCl buffer (pH 7.4), 10 mM EDTA, $30 \%$ Triton-1000, $10 \%$ SDS, protease inhibitors cocktails (Roche), and $\mathrm{NaCl}$, using a homogenizer. Homogenates were centrifuged at 5,000g for $10 \mathrm{~min}$ at $4{ }^{\circ} \mathrm{C}$. Equal amounts of protein (quantized by BCA method) were resolved by SDS-PAGE on $4-12 \%$ gels, transferred to nitrocellulose, and incubated with antibodies against either $\operatorname{Nav} \beta 2$ (1:500, Alomone) or Nav1.1 $\alpha$ (1:800, Alomone). $\beta$-actin (mouse monoclonal anti- $\beta$-actin, 1:800, Santa Cruz, Delaware, CA) was used as a reference. Nitrocellulose membranes were washed and incubated with peroxidase-conjugated anti-mouse secondary antibodies (1:10,000, Santa Cruz), and were detected using enhanced chemiluminescence reagent (Pierce). Signals were quantified using a ChemiDoc ${ }^{\mathrm{TM}}$ $\mathrm{XRS}+$ imaging system with Image $\mathrm{Lab}^{\mathrm{TM}}$ software (BioRad, USA).

\section{Quantitative RT-PCR}

Samples were obtained for Nav $\beta 2$ detection via reverse transcription and quantitative real-time PCR (qRT-PCR) as previously described [27]. The relative CT method was used to compare difference between samples. Fold decrease/increase was determined relative to a blank control after normalized to a housekeeping gene $\beta$-actin housekeeping gene using $2^{-\Delta \Delta \mathrm{CT}}$.

\section{Cell surface biotinylation assay}

Hippocampal and cortical cortex tissues were collected from Tg mice (eight months old) with different genotypes ( $\mathrm{n}=15$ in each group). Cell surface biotinylation and detection of surface Nav1.1 $\alpha$ subunits were performed as previously described $[13,23]$. NeutrAvidin-agarose beads (Pierce) were employed to pull down biotinylated proteins.

\section{Morris Water Maze Test}

The Morris water maze (MWM) consisted of a circular pool (100 cm diameter, $50 \mathrm{~cm}$ deep) filled with water at $24-26^{\circ} \mathrm{C}$ to a depth of $20 \mathrm{~cm}$. The MWM test followed as previously described [23]. Percentages of time spent in the target quadrant, path in the target quadrant, and number of target platform crossings were recorded.

\section{Electrophysiological patch clamp recording}

Brains were removed from anesthetized 7-8 weeks-

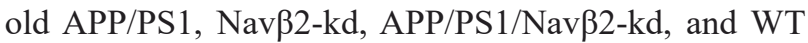
mice ( $\mathrm{n}=15$ per group), and placed in anoxygenated $\left(95 \% \mathrm{O}_{2} / 5 \% \mathrm{CO}_{2}\right.$ ) artificial cerebrospinal fluid (ACSF) at $4{ }^{\circ} \mathrm{C}$. Whole cell recordings of voltage-gated sodium currents in hippocampal slices from different genotype mice were performed as previously described [28]. Cells were clamped using a MultiClamp 700B amplifier (Molecular Devices Corp., Sunnyvale, CA, USA) in conjunction with a Digidata 1322 A interface (Axon Instruments, Union City, CA, USA) at a holding potential of $-70 \mathrm{mV}$. pCLAMP 9.2 software (Molecular Devices Corp.) was used for current recording and analyzing. Voltage command protocols were as described previously [28]. The peak amplitude of the second sodium current 
response divided by the response at the maximal interval was plotted as a function of the interpulse interval. Curves were fitted with a double rising exponential function.

\section{Electroencephalogram (EEG) recordings}

APP/PS1, Navß2-kd, APP/PS1/Nav $\beta 2-k d$ (eight months old) and age matched WT littermate mice were anesthetized for EEG recordings by using nanofabricated polyimide-based microelectrodes (PBM-array) $(n=15$ per group). PBM-array surgical implantation on mouse skulls and EEG recordings were performed as previously described [29] with some modifications.

EEG signals were interpolated to $128 \mathrm{~Hz}$ and bandpass filtered from 1 to $64 \mathrm{~Hz}$. Power spectral densities (PSDs) were generated every $30 \mathrm{~s}$ for each recording to calculate the amount of time spent at $>6 \mathrm{~Hz}$ (time in high frequency). Signal processing ensured that integer values represented the dominant frequency (DF) in $\mathrm{Hz}$ for each $30 \mathrm{~s}$ epoch. Average DF was calculated for each mouse from each DF in each $30 \mathrm{~s}$ epoch. Time in high frequency was calculated by summing the number of $30 \mathrm{~s}$ epochs with a DF $>6 \mathrm{~Hz}$ and dividing it by the total number of 30 s epochs (total time of the recording) for each mouse [13].

\section{Cell culture}

The hippocampus of APP/PS1, Nav $32-k d$, APP/ $\mathrm{PS} 1 / \mathrm{Nav} \beta 2-\mathrm{kd}$, and WT mice were completely removed following craniotomy. These were dissected into $1 \mathrm{~mm}^{3}$ slices in PBS using an anatomic microscope, and then digested for $30 \mathrm{~min}$ at $37^{\circ} \mathrm{C}$ using $2 \mathrm{mg} / \mathrm{ml}$ Papain (Roche) containing $2 \mu \mathrm{l} / \mathrm{ml}$ DNAase. Digestion was terminated by addition of an equal volume of Dulbecco's modified Eagle's medium (DMEM) supplemented with 10\% fetal bovine serum (FBS) and 1\% penicillin-streptomycin. The cell suspension was centrifuged at $1,000 \mathrm{rpm}$ for $10 \mathrm{~min}$ at $4^{\circ} \mathrm{C}$. After discarding the supernatant, cells were resuspended in the same medium by gently pipetting up and down and were seeded on $24-w e l l$ plates at $2 \times 10^{5}$ cells $/ \mathrm{ml}$. Medium was replaced with Neurobasal (GIBCO) medium supplemented with 2\% B27 supplement and 1\% penicillin/ streptomycin.

\section{ELISA detection of A $\beta$ levels}

After five days of culture, mediums was collected from APP/PS1, Nav $\beta 2-k d$, APP/PS1/Nav $32-k d$, and WT mouse cell cultures. $A \beta 40$ and $A \beta 42$ levels were measured via ELISA (Demeditec Diagnostics GmbH, German) according to the manufacturer's instructions. A $\beta$ levels in cell culture media were compared between different genotypes.

\section{Solution APP measurement}

A $\quad$ SAPP $\alpha /$ sAPP $\beta \quad$ multiplex electrochemiluminescence assay (ECLIA; Meso Scale Discovery) kit was used to quantify $\operatorname{sAPP} \alpha$ and $\beta$. Before harvesting, cells were conditioned in serum-free medium for $16 \mathrm{~h}$. Cell medium was then collected and sAPP $\alpha$ and $\beta$ were quantified according to the manufacturer's instructions.

\section{Statistical analysis}

We used the SPSS 19.0 for Windows covariance software package for statistical analysis. Results are expressed as the means \pm standard deviation (SD). Differences between two groups were evaluated using Student's t test. One-variable experiments with more than two groups were evaluated using ANOVA followed by Bonferroni's post hoc tests. Electrophysiological patch clamp recording data were analyzed via one-way ANOVA, followed by Student's t-test for paired groups (two tailed). Tow-way repeated-measures ANOVA followed by Tukey's test were employed for MWM test analysis. $P<0.05$ was considered significant.

\section{ACKNOWLEDGMENTS}

The authors would like to thank Doctor Wei-Yan $\mathrm{Hu}$ and Sarah Frank for their technical support.

\section{CONFLICTS OF INTEREST}

The authors declare that they have no conflicts of interest.

\section{FUNDING}

This work is supported by the National Natural Science Foundation of China (Grant Nos. 81560238 and 81502377), the Fund of the Applied Basic Research Programs of Yunnan Province in China (Grant Nos. 2016FB139 and 2016FB123), and the Special Fund of the Applied Basic Research Programs of Yunnan Province associated with Kunming Medical University in China (Grant Nos. 2015FB001 and 2014FB087).

\section{REFERENCES}

1. Ridge PG, Ebbert MT, Kauwe JS. Genetics of Alzheimer's disease. BioMed Res Int. 2013; 2013:254954.

2. Ebbert MT, Ridge PG, Kauwe JS. Bridging the gap between statistical and biological epistasis in Alzheimer's disease. BioMed Res Int. 2015; 2015:870123.

3. Ballard C, Gauthier S, Corbett A, Brayne C, Aarsland D, 
Jones E. Alzheimer's disease. Lancet. 2011; 377:1019-31.

4. Vossel KA, Tartaglia MC, Nygaard HB, Zeman AZ, Miller BL. Epileptic activity in Alzheimer's disease: causes and clinical relevance. Lancet Neurol. 2017; 16:311-22.

5. Kazim SF, Chuang SC, Zhao W, Wong RK, Bianchi R, Iqbal K. Early-Onset Network Hyperexcitability in Presymptomatic Alzheimer's Disease Transgenic Mice Is Suppressed by Passive Immunization with Anti-Human APP/A $\beta$ Antibody and by mGluR5 Blockade. Front Aging Neurosci. 2017; 9:71.

6. Palop JJ, Chin J, Roberson ED, Wang J, Thwin MT, BienLy N, Yoo J, Ho KO, Yu GQ, Kreitzer A, Finkbeiner S, Noebels JL, Mucke L. Aberrant excitatory neuronal activity and compensatory remodeling of inhibitory hippocampal circuits in mouse models of Alzheimer's disease. Neuron. 2007; 55:697-711.

7. Minkeviciene R, Rheims S, Dobszay MB, Zilberter M, Hartikainen J, Fülöp L, Penke B, Zilberter Y, Harkany T, Pitkänen A, Tanila H. Amyloid beta-induced neuronal hyperexcitability triggers progressive epilepsy. J Neurosci. 2009; 29:3453-62.

8. Harris JA, Devidze N, Verret L, Ho K, Halabisky B, Thwin MT, Kim D, Hamto P, Lo I, Yu GQ, Palop JJ, Masliah E, Mucke L. Transsynaptic progression of amyloid- $\beta$-induced neuronal dysfunction within the entorhinal-hippocampal network. Neuron. 2010; 68:428-41.

9. Roberson ED, Halabisky B, Yoo JW, Yao J, Chin J, Yan F, Wu T, Hamto P, Devidze N, Yu GQ, Palop JJ, Noebels JL, Mucke L. Amyloid- $\beta /$ Fyn-induced synaptic, network, and cognitive impairments depend on tau levels in multiple mouse models of Alzheimer's disease. J Neurosci. 2011; 31:700-11.

10. Lozsadi DA, Larner AJ. Prevalence and causes of seizures at the time of diagnosis of probable Alzheimer's disease. Dement Geriatr Cogn Disord. 2006; 22:121-24.

11. Verret L, Mann EO, Hang GB, Barth AM, Cobos I, Ho K, Devidze N, Masliah E, Kreitzer AC, Mody I, Mucke L, Palop JJ. Inhibitory interneuron deficit links altered network activity and cognitive dysfunction in Alzheimer model. Cell. 2012; 149:708-21.

12. Bakker A, Krauss GL, Albert MS, Speck CL, Jones LR, Stark CE, Yassa MA, Bassett SS, Shelton AL, Gallagher M. Reduction of hippocampal hyperactivity improves cognition in amnestic mild cognitive impairment. Neuron. 2012; 74:467-74.

13. Corbett BF, Leiser SC, Ling HP, Nagy R, Breysse N, Zhang X, Hazra A, Brown JT, Randall AD, Wood A, Pangalos $\mathrm{MN}$, Reinhart $\mathrm{PH}$, Chin J. Sodium channel cleavage is associated with aberrant neuronal activity and cognitive deficits in a mouse model of Alzheimer's disease. J Neurosci. 2013; 33:7020-26.

14. Llinás RR. The intrinsic electrophysiological properties of mammalian neurons: insights into central nervous system function. Science. 1988; 242:1654-64.
15. Dhar Malhotra J, Chen C, Rivolta I, Abriel H, Malhotra R, Mattei LN, Brosius FC, Kass RS, Isom LL. Characterization of sodium channel alpha- and beta-subunits in rat and mouse cardiac myocytes. Circulation. 2001; 103:1303-10.

16. Vijayaragavan K, Powell AJ, Kinghorn IJ, Chahine M. Role of auxiliary beta1-, beta2-, and beta3-subunits and their interaction with $\mathrm{Na}(\mathrm{v}) 1.8$ voltage-gated sodium channel. Biochem Biophys Res Commun. 2004; 319:53140.

17. Bechtold DA, Smith KJ. Sodium-mediated axonal degeneration in inflammatory demyelinating disease. J Neurol Sci. 2005; 233:27-35.

18. Waxman SG. Axonal conduction and injury in multiple sclerosis: the role of sodium channels. Nat Rev Neurosci. 2006; 7:932-41.

19. O’Malley HA, Shreiner AB, Chen GH, Huffnagle GB, Isom LL. Loss of $\mathrm{Na}+$ channel beta2 subunits is neuroprotective in a mouse model of multiple sclerosis. Mol Cell Neurosci. 2009; 40:143-55.

20. Chen C, Bharucha V, Chen Y, Westenbroek RE, Brown A, Malhotra JD, Jones D, Avery C, Gillespie PJ 3rd, KazenGillespie KA, Kazarinova-Noyes K, Shrager P, Saunders TL, et al. Reduced sodium channel density, altered voltage dependence of inactivation, and increased susceptibility to seizures in mice lacking sodium channel beta 2-subunits. Proc Natl Acad Sci USA. 2002; 99:17072-77.

21. Lopez-Santiago LF, Pertin M, Morisod X, Chen C, Hong S, Wiley J, Decosterd I, Isom LL. Sodium channel beta2 subunits regulate tetrodotoxin-sensitive sodium channels in small dorsal root ganglion neurons and modulate the response to pain. J Neurosci. 2006; 26:7984-94.

22. Kim DY, Carey BW, Wang H, Ingano LA, Binshtok AM, Wertz MH, Pettingell WH, He P, Lee VM, Woolf CJ, Kovacs DM. BACE1 regulates voltage-gated sodium channels and neuronal activity. Nat Cell Biol. 2007; 9:75564.

23. XiYang YB, Wang YC, Zhao Y, Ru J, Lu BT, Zhang YN, Wang NC, Hu WY, Liu J, Yang JW, Wang ZJ, Hao CG, Feng ZT, et al. Sodium Channel Voltage-Gated Beta 2 Plays a Vital Role in Brain Aging Associated with Synaptic Plasticity and Expression of COX5A and FGF-2. Mol Neurobiol. 2016; 53:955-67.

24. Wong HK, Sakurai T, Oyama F, Kaneko K, Wada K, Miyazaki H, Kurosawa M, De Strooper B, Saftig P, Nukina N. beta Subunits of voltage-gated sodium channels are novel substrates of beta-site amyloid precursor proteincleaving enzyme (BACE1) and gamma-secretase. J Biol Chem. 2005; 280:23009-17.

25. Wang H, Liu J, Zong Y, Xu Y, Deng W, Zhu H, Liu Y, Ma C, Huang L, Zhang L, Qin C. miR-106b aberrantly expressed in a double transgenic mouse model for Alzheimer's disease targets TGF- $\beta$ type II receptor. Brain Res. 2010; 1357:166-74.

26. Li XY, Bao XJ, Wang RZ. Potential of neural stem cell- 
based therapies for Alzheimer's disease. J Neurosci Res. 2015; 93:1313-24.

27. Hu T, Li YS, Chen B, Chang YF, Liu GC, Hong Y, Chen HL, Xiyang YB. Elevated glucose-6-phosphate dehydrogenase expression in the cervical cancer cases is associated with the cancerigenic event of high-risk human papillomaviruses. Exp Biol Med (Maywood). 2015; 240:1287-97.

28. Li S, Wang X, Ma QH, Yang WL, Zhang XG, Dawe GS, Xiao ZC. Amyloid precursor protein modulates Nav1.6 sodium channel currents through a Go-coupled JNK pathway. Sci Rep. 2016; 6:39320.

29. Lee M, Kim D, Shin HS, Sung HG, Choi JH. High-density EEG recordings of the freely moving mice using polyimidebased microelectrode. J Vis Exp. 2011; 11:47.

30. Kovacs DM, Gersbacher MT, Kim DY. Alzheimer's secretases regulate voltage-gated sodium channels. Neurosci Lett. 2010; 486:68-72.

31. Tamagnini F, Scullion S, Brown JT, Randall AD. Intrinsic excitability changes induced by acute treatment of hippocampal CA1 pyramidal neurons with exogenous amyloid $\beta$ peptide. Hippocampus. 2015; 25:786-97.

32. Sanchez PE, Zhu L, Verret L, Vossel KA, Orr AG, Cirrito JR, Devidze N, Ho K, Yu GQ, Palop JJ, Mucke L. Levetiracetam suppresses neuronal network dysfunction and reverses synaptic and cognitive deficits in an Alzheimer's disease model. Proc Natl Acad Sci USA. 2012; 109:E2895903.
33. Gordon JA. Oscillations and hippocampal-prefrontal synchrony. Curr Opin Neurobiol. 2011; 21:486-91.

34. Vann SD, Albasser MM. Hippocampus and neocortex: recognition and spatial memory. Curr Opin Neurobiol. $2011 ; 21: 440-45$.

35. Muzzio IA, Kentros C, Kandel E. What is remembered? Role of attention on the encoding and retrieval of hippocampal representations. J Physiol. 2009; 587:283754.

36. Derdikman D, Moser EI. A manifold of spatial maps in the brain. Trends Cogn Sci. 2010; 14:561-69.

37. Decock M, El Haylani L, Stanga S, Dewachter I, Octave JN, Smith SO, Constantinescu SN, Kienlen-Campard P. Analysis by a highly sensitive split luciferase assay of the regions involved in APP dimerization and its impact on processing. FEBS Open Bio. 2015; 5:763-73.

38. Hardy J, Selkoe DJ. The amyloid hypothesis of Alzheimer's disease: progress and problems on the road to therapeutics. Science. 2002; 297:353-56.

39. Wang X, Zhang XG, Zhou TT, Li N, Jang CY, Xiao ZC, Ma QH, Li S. Elevated Neuronal Excitability Due to Modulation of the Voltage-Gated Sodium Channel Nav1.6 by $A \beta 1-42$. Front Neurosci. 2016; 10:94. 